\title{
Por uma crítica ao conceito de desenvolvimento sustentável
}

\section{For a critique of the concept of sustainable development}

\author{
Fabio Vizeu ${ }^{1}$ \\ Francis Kanashiro Meneghetti ${ }^{2}$ \\ Rene Eugenio Seifert ${ }^{3}$
}

\section{Resumo}

O objetivo deste texto é ensaiar uma crítica ao conceito de desenvolvimento sustentável, por meio da articulação de argumentos para se confrontar a visão aparente desse conceito, vislumbrando sua essência ideológica que, de forma nada ingênua, cria uma falsa noção de conciliação entre o capitalismo e a questão ecológica. Para se alcançar esse objetivo, busca-se, na perspectiva Frankfurtiana, a base metodológica para ensaiar esta crítica. Apresentam-se, dessa forma, os fundamentos da contradição do conceito de desenvolvimento sustentável sob a ótica da lógica interna do capitalismo, demonstrando a impossibilidade de conciliação entre uma suposta prática ecologicamente viável com os objetivos desse sistema.

Palavras-chave: Desenvolvimento Sustentável. Sustentabilidade. Estudos Organizacionais. Ideologia. Crise Ecológica.

\begin{abstract}
This paper critically assesses the concept of sustainable development. It articulates arguments that challenge the dominant view of the concept by exposing its ideological essence, which falsely represents the possibility of reconciling capitalism and solutions to the ecological crisis. The methodological basis for this reflection draws upon the critical perspective of the Frankfurt School. The paper discusses major contradictions of the concept in the capitalist system, and argues about the impossibility of reconciling an alleged ecologically responsible practice with the logics and aims of such system.
\end{abstract}

Keywords: Sustainable Development. Sustainability. Organization Studies. Ideology. Ecological Crisis.

Artigo submetido em 27 de julho de 2012 e aceito para publicação em 16 de agosto de 2012.

${ }^{1}$ Doutor em Administração pela EAESP/FGV; Professor Adjunto do Mestrado em Administração da UNIGRANRIO. Endereço: Rua da Lapa, 86, Centro, CEP 20021-180, Rio de Janeiro - RJ, Brasil. E-mail fabio.vizeu@gmail.com

2 Doutor em Educação pela UFPR; Professor do Departamento Acadêmico de Gestão e Economia e do Programa de Pós-Graduação em Tecnologia da UTFPR. Endereço: Av. Sete de Setembro 3165, PPGTE - Sala 5, Bairro Rebouças, CEP 80230-901, Curitiba - PR, Brasil. E-mail francis@utfpr.edu.br

${ }^{3}$ Doutor em Administração pela Universidade de Birmingham - Inglaterra; Professor da Universidade Positivo; Pesquisador do Instituto Brasileiro de Estudos e Pesquisas Sociais - IBEPES. Endereço: Universidade Positivo - Programa de Mestrado e Doutorado em Administração, Rua Prof. Pedro Viriato Parigot de Souza, 5300, Campo Comprido, CEP 81280-330, Curitiba - PR, Brasil. E-mail r.e.seifert@gmail.com 


\section{Introdução}

O pensamento e a ação se unem na constituição histórica da realidade social tal como duas forças que ora se confrontam, ora convergem para o mesmo ponto, relação essa que abriga o maior debate do pensamento filosófico moderno (ANDERY et al., 2007), sob a dinâmica de contínua reconstrução, em que a ideia se subverte ao fato concreto, mas também condiciona a ação coletiva para uma direção determinada. Nesse sentido, pensamento e ação não constituem um binômio que deve ser compreendido apenas antagonicamente, já que não se pode negar a força da ação do pensamento, quando se leva em conta o lugar das ideias no mundo concreto da vida em sociedade.

Entre as várias formas de compreensão do lugar do pensamento no processo de construção histórica da realidade, uma que revela boa parte das contradições do mundo em que vivemos é aquela que aponta o conteúdo ideológico dos conceitos de implicação política que surgem em determinados contextos históricos. Tais conceitos abarcam conteúdos semânticos que reforçam realidades sociais concretas, vislumbrando um horizonte de expectativa utopicamente articulado pelos interesses de uma estrutura política dominante (KOSELLECK, 2006). Na era moderna - cuja estrutura política vigente é o capitalismo - vários conceitos emergem com o propósito de reafirmação do sistema social e político dominante: democracia, desenvolvimento, progresso, competitividade e - mais recentemente - desenvolvimento sustentável.

Acerca deste último, nota-se que ele emerge de condições particulares de contradição do sistema capitalista, uma vez que, no surgimento da ideia de sustentabilidade, destacam-se os efeitos nocivos que o avanço desse sistema trouxe para o planeta, particularmente, para a questão ecológica. Nestes termos, firma-se como conceito orientador de esforços coletivos tanto de Estados e entidades governamentais nacionais e supranacionais, como para organizações não governamentais e empresas preocupadas com a questão ecológica. Notadamente, a necessidade de desenvolvimento sustentável foi um dos principais aspectos reforçados na Conferência das Nações Unidas: Rio +20 .

Apesar disso, o entendimento dominante do conceito fundamenta-se em uma concepção conciliatória com o capitalismo, que deixa transparecer uma ambígua relação entre as condições históricas de sua emergência como ideia pretensamente reparadora da atual crise socioambiental e de seu real sentido de reforço da lógica do capital. De forma muito clara, essa ambiguidade assinala o caráter ideológico que o conceito apresenta.

Dada essa contradição, o objetivo deste texto é ensaiar uma crítica ao conceito de desenvolvimento sustentável tal qual este se apresenta nas áreas de administração e organizações. A intenção, portanto, é articular argumentos que permitam que se abandone a visão aparente desse conceito - disseminada nos veículos de comunicação de massa, aplaudida pelo meio empresarial e aplicada nas políticas públicas pelos governos dos Estados capitalistas - para que se possa entrever sua essência ideológica que, de forma nada ingênua, trabalha a serviço do capitalismo. Dito de outra forma, o principal intento é dissipar a névoa que desvia a atenção sobre os problemas reais e cada vez mais agudos da prática econômica capitalista, névoa esta que cria uma falsa noção de conciliação entre o capitalismo e a questão ecológica.

Para se fundamentar esse objetivo, sob o ponto de vista metodológico, busca-se, na perspectiva frankfurtiana, a base metodológica para ensejar no presente trabalho uma reflexão delineada nos critérios do projeto intelectual da Teoria Crítica. Por isso, apresentam-se as bases deste projeto intelectual, recuperando as ideias de Horkheimer sobre o pensamento crítico, de tal forma que este constitua a justificativa e o critério de sua elaboração.

Além desta introdução, este texto é estruturado em cinco partes. Primeiramente, são apresentados os princípios frankfurtianos do ensaio crítico como método de pensamento, demarcando-os como os critérios analíticos para a elaboração do presente trabalho. Em seguida, expõe-se o conceito dominante de sustentabilidade, indicando as condições históricas de sua emergência e como se vinculou ao projeto desenvolvimentista dos Estados capitalistas. Na terceira parte, são discutidas as premissas do capitalismo 
reproduzidas no conceito de desenvolvimento sustentável e, na quarta parte, apontam-se alguns aspectos de contradição que sugerem a impossibilidade de conciliação entre uma suposta prática ecologicamente viável com os objetivos do empreendimento econômico capitalista. Nas considerações finais, recuperam-se os pressupostos da teoria crítica apontados na primeira parte para o projeto ensaístico pretendido, ou seja, revelando a sustentabilidade desenvolvimentista como um mecanismo ideológico de construção do aparente a serviço do capitalismo.

\section{Ensaio Crítico como Método}

Os estudos críticos veem-se destacados nos estudos organizacionais no Brasil (PAULA, MARANHÃO e BARROS, 2009; ALCADIPANI e TURETA, 2009; FARIA, 2009; MISOCZKY et al., 2009; TENÓRIO, 2009). Significativa parte dos estudos críticos está fundamentada em autores da Escola de Frankfurt. Adorno e Horkheimer estão entre os mais expressivos representantes do movimento chamado Teoria Crítica da Sociedade, cuja concepção, segundo Bottomore (1984; 1998), tem sido associada à Escola de Frankfurt, que tinha como objetivo compreender o capitalismo como sistema econômico social totalizante. Vincularam-se ao marxismo como fundamento analítico da sociedade, mas ao mesmo tempo foram críticos de "certos marxismos" como o mecanicista, o naturalista, os de versões fiscalistas da história e outros, aliando as contribuições teóricas de outros expressivos pensadores como Kant, Freud e Weber, incorporando-as nas análises dialéticas dos acontecimentos sociais da época.

No texto "Teoria Tradicional e Teoria Crítica", Horkheimer (1991a) apresenta os fundamentos da Teoria Crítica. Segundo ele, "a teoria crítica não se deixa enganar pela aparência, isto é, pela ilusão fomentada meticulosamente nas ciências sociais, de que propriedade e lucro não desempenhariam mais o papel decisivo" (HORKHEIMER, 1991a, p. 64). Seus fundamentos estão embasados na tendência de o capitalismo instituir-se como sistema econômico totalitário, influenciando todas as dimensões da vida social e estendendo suas análises para o campo da ciência, que considera ser uma força produtiva a serviço dos interesses dos grupos dominantes. Todavia, não faz uma interpretação mecanicista ou fatalista da ciência no contexto econômico dominante, pelo contrário, sua interpretação é dialética, sempre mostrando as contradições encontradas na realidade.

Horkheimer opõe a teoria crítica à teoria tradicional, uma forma dominante de racionalidade que se instituiu nas ciências. Para ele, no texto "Filosofia e Teoria Crítica":

A teoria em sentido tradicional, cartesiano, como a que se encontra em vigor em todas as ciências especializadas, organiza a experiência à base da formulação de questões que surgem em conexão com a reprodução da vida dentro da sociedade atual. Os sistemas das disciplinas contêm os conhecimentos de tal forma que, sob circunstâncias dadas, são aplicáveis ao maior número possível de ocasiões. A gênese social dos problemas, as situações reais, nas quais a ciência é empregada e os fins perseguidos em sua aplicação, são por elas mesmas consideradas exteriores. - A teoria crítica da sociedade, ao contrário, tem como objeto os homens como produtores de todas as suas formas históricas de vida. (HORKHEIMER, 1991b, p. 69)

A teoria tradicional apresenta-se na aparência como conhecimento autônomo, destituído de relações com a base de produção das condições de existência dos indivíduos. Esse distanciamento da teoria tradicional tem como consequência o ocultamento da mesma realidade que rege o mundo do trabalho no sistema de capital: a separação entre trabalho manual e intelectual. A teoria tradicional, de representação cartesiana tal como fundamenta Horkheimer em seu texto, é a consagração da concepção burguesa de que o pensar é a instância máxima que um indivíduo pode alcançar. Baseando-se nos princípios racionalistas, considera-se que quem pensa superou a condição mundana do fazer. A teoria tradicional, com seus pressupostos cartesianos, é a 
negação do homem como agente produtor das próprias condições de existência, ao mesmo tempo em que se apresenta como forma 'superior de saber' que consolida a onipotência da ciência burguesa.

Por isto, Horkheimer (1991a, p. 37) afirma que a "representação tradicional da teoria é abstraída do funcionamento da ciência, tal como este ocorre a um nível dado da divisão do trabalho." A teoria tradicional é na realidade resultado das atividades científicas sob a mesma lógica das demais atividades sociais, mais especificamente a lógica do trabalho. A produção científica sob a batuta da teoria tradicional nada mais é do que uma dimensão que se soma às demais áreas produtivas do homem na atualidade. Assim, "a vida da sociedade é um resultado da totalidade do trabalho nos diferentes ramos de profissão, e mesmo que a divisão do trabalho funcione mal sob o modo de produção capitalista, os ramos, e dentre eles a ciência, não podem ser vistos como autônomos e independentes." (HORKHEIMER, 1991a, p. 37)

Isto posto, um dos papéis centrais da teoria crítica é tentar esclarecer sobre a importância da teoria tradicional - e consequentemente das ciências - sem, contudo, fazer do próprio esclarecimento um novo mito, tão bem alertado por Adorno e Horkheimer (1985) na obra "Dialética do Esclarecimento". A teoria crítica é um empreendimento radical, no sentido filosófico de ir à raiz na compreensão de algo. Seus fundamentos estão baseados em uma construção histórica originária das práxis analíticas da sociedade e das trajetórias, sobretudo de Adorno, Hokheimer e Marcuse, principais representantes da Escola de Frankfurt.

Apesar de haver diferenças e divergências teóricas entre esses autores, e analisando as principais obras de Horkheimer (1986; 1990; 1991a; 1991b; 2000) e as dele com Adorno (ADORNO e HORKHEIMER, 1985), é possível identificar as principais categorias que fundamentam a Teoria Crítica.

A primeira delas é compreender as contradições produzidas nos sistemas de produção capitalista e em todas as instâncias sociais relacionadas à produção das condições de existência dos indivíduos. Por ser a dialética hegeliana na versão materialista o método de análise dominante entre os teóricos críticos (ressaltando-se as diferenças entre eles referentes ao uso do método), a compreensão das contradições é central para entender a realidade que se apresenta como aparência. Na teoria tradicional, o real se mostra como aparência formal, escondendo as contradições existentes. A teoria crítica tem como princípio revelar as contradições, desvelando o real e mostrando que a aparência quase sempre não corresponde com à essência.

A segunda é questionar as racionalidades dominantes. A instituição de um sistema econômico, que transforma os indivíduos em meio e não em fim em si mesmos, já demonstra como a racionalidade instrumental tornou-se dominante na orientação das relações sociais. O capitalismo, que tem como fim o lucro e acúmulo cada vez maior de capital, instrumentaliza as relações e impõe a racionalidade do "cálculo utilitário de consequências" como a própria engrenagem do sistema de produção da existência dos indivíduos. Por esse motivo, o pragmatismo, na versão predominantemente utilitarista, tornou-se a filosofia e a ideologia dominante - da sociedade baseada em formações de racionalidades que servem como sistemas orientadores da vida em sociedade. A teoria crítica tem como objetivo questionar as racionalidades para recolocar os indivíduos como fim em si mesmos sem, contudo, cair no pensamento antropocêntrico que ainda fundamenta a ideologia burguesa. O questionamento das racionalidades pressupõe refletir criticamente as próprias racionalidades que possam ser instituídas pelos chamados seguidores da teoria crítica.

Entender o contexto social-histórico é a terceira categoria de suma importância. A teoria tradicional tem como característica destituir o elemento histórico para compreensão da realidade. As análises baseadas em racionalidades funcionais das relações causa-efeito limitadas às variáveis percebidas e destituídas de um movimento maior baseado na relação tempo-espaço faz com que o entendimento das realidades se restrinja às verdades formadas apenas da apresentação do fenômeno ocorrido na unidade da consciência do indivíduo. A teoria crítica coloca o indivíduo no processo histórico, tornando-o elemento central da construção da própria história e, ao mesmo tempo, pertencente ao movimento maior da história da humanidade. $\mathrm{O}$ social forma-se do movimento dialético do espaço-tempo sem que os indivíduos sejam meros "personagens" sociais. Contudo, ao mesmo tempo, procura compreender em que medida os indivíduos são de fato agentes 
de mudanças e participam da construção da história como sujeitos autônomos e pertencentes a uma coletividade que age contraditoriamente na construção de sua existência.

A quarta é examinar as ideologias. "A ideologia" - aqui entendida como ente imaginário unificado - tornouse ela mesma um recurso de poder e controle do capital sobre o trabalho, isso porque ela "intervém implicitamente em todos os juízos filosóficos da sociedade humana" (HORKHEIMER 1986, p. 14), estando também presente no senso comum, no bom senso e nas racionalidades religiosas e científicas, de cujas criações advém seu poder de persuasão conformando tanto o pensamento como o sentimento dos indivíduos. Por isso, toda ideologia é uma "gaiola psíquica" para o indivíduo, aprisionando-o nos limites das racionalidades instituídas. Justamente, a teoria crítica procura examinar as ideologias para tentar compreender de que forma as racionalidades podem aprisioná-lo ao invés de emancipá-lo.

A quinta é promover a emancipação individual e coletiva, que é o próprio objetivo da teoria crítica. Emancipar é refletir criticamente sobre a realidade em que os sujeitos estão inseridos, não se limitando, portanto, ao simples ato de pensar a realidade, mas de transformá-la por meio da práxis. Emancipar não é renunciar ao esclarecimento, é incorporá-lo e distingui-lo da simples ação de domínio sobre a natureza e requer entender o indivíduo no seu contexto social-histórico, de forma a fazer de todos os agentes senhores de suas ações.

As cinco categorias da teoria crítica são orientadoras das contribuições dos teóricos críticos frankfurtianos. Suas reflexões sempre abrangeram a multidisciplinaridade de conhecimentos para entender o que acontecia na sua época, sobretudo em relação ao capitalismo e ao fenômeno do nazismo. Mas, como os teóricos críticos apresentaram suas reflexões?

Comumente, Adorno e Horkheimer são lembrados por terem utilizado o ensaio como forma de apresentação de suas análises, reflexões e críticas sociais, sendo um equívoco pressupor que os estudos deles não estão fundamentados em evidências empíricas. Seus estudos sobre a Indústria Cultural (ADORNO e HORKHEIMER, 1985) estão baseados em uma série de relatórios de pesquisas e coletas de dados que sustentam as análises desenvolvidas e apresentadas na forma ensaística, assim como uma série de outros estudos publicados. Posteriormente, Adorno (1986) escreve o "Ensaio como forma", texto que esclarece sobre o método do ensaio como forma de apresentação, reflexão e análise da realidade.

Segundo Adorno (1986, p. 179), o "ensaio obriga a pensar a coisa, desde o primeiro passo, em tantos níveis distintos quantos nela existem, sendo assim um corretivo daquela rígida primitividade, que sempre se associa à ratio corrente" (ADORNO, 1986, p. 179). Caracteriza-se por não ter uma estrutura definitiva, um modelo acabado, um procedimento padronizado ou uma razão formal corrente e usual, possível de ser replicada como ocorre nos estudos científicos tradicionais. O ensaísta é quem "rege" a reflexão por ser ele mesmo o sujeito da construção dialética do conhecimento sem cair na onipotência do próprio pensamento. Isto ocorre porque a "a unidade do ensaio é determinada pela unidade do seu objeto, junto com a da teoria e da experiência que se encarnaram nele." (ADORNO, 1986, p. 181).

Ainda que o ensaio seja frequentemente confundido como estudo teórico ou simplesmente como revisão teórica, o ensaio se realiza no percurso da sua realização, isto é, no próprio andamento das reflexões do ensaísta em aproximação com o objeto do ensaio. Dessa forma, o ensaio não se apresenta como sistema definitivo. As reflexões se formam da relação dialética entre sujeito e objeto, tendo este primazia na orientação desse processo, levando-se em consideração forma e conteúdo, aparência e essência, fato e fenômeno e como eles se apresentam no próprio vir a ser na formulação do ensaio. Assim, renuncia-se ao formalismo e ao dogmatismo da ciência porque é uma forma de transgressão à racionalidade dominante.

Este ensaio crítico sobre a concepção de desenvolvimento sustentável adota os fundamentos da teoria crítica e o método do ensaio na sua acepção original, ou seja, baseada nas concepções de Adorno (1986). 


\section{Raízes Históricas do Desenvolvimento Sustentável}

Nas últimas décadas, o ideal desenvolvimentista de prosperidade e progresso apregoados no discurso capitalista torna-se cada vez mais longe de ser realizado (SACHS, 2000b). Este sentimento não é potencializado somente pelas recorrentes crises econômico-financeiras, mas também pela cada vez mais evidente injustiça social, dizimação da biodiversidade natural e das bruscas mudanças climáticas. Como observou Shrivastava (1995, p. 936):

O desenvolvimento industrial dos últimos 200 anos trouxe imensurável riqueza e prosperidade. No entanto, também causou degradação ecológica não intencional. Como resultado, o Planeta enfrenta inúmeros problemas ambientais, incluindo o aquecimento global, destruição da camada de ozônio, desmatamento e desertificação, declínio da biodiversidade, chuva ácida, acidentes industriais e resíduos tóxicos (tradução nossa).

Foi principalmente a partir dos anos 1970 que o alarme ecológico ganhou destaque no debate político internacional, reforçado por estudos como os de Rachel Carson (1962) que, em 1962, demonstrou os efeitos danosos do Dicloro-Difenil-Tricloroetano (o "DDT") sobre animais e seres humanos; e pelo relatório do Clube de Roma (MEADOWS, 1972) sobre os limites do crescimento (este último, um dos livros sobre ambiente mais vendido na história). Com base em modelos matemáticos desenvolvidos por pesquisadores do Massachusetts Institute of Technology (MIT), esses esforços procuravam demonstrar que o planeta não suportaria o crescimento econômico e populacional ilimitado com base em recursos naturais finitos. Além disso, ressoava ainda o movimento hippie às questões ambientais, bem como a crise do petróleo, que, no início dos anos 1970, alertava para a dependência de recursos naturais e para a real possibilidade de sua exaustão.

A crescente preocupação com a questão ambiental mobilizou iniciativas governamentais e não governamentais no intuito de se discutirem e se proporem soluções. Entre elas, em 1972, a Organização das Nações Unidas realizou a Primeira Conferência Mundial sobre o Homem e o Meio Ambiente, responsável por introduzir as preocupações ambientais na agenda política do desenvolvimento. No entanto, em vista dos resultados alcançados terem sido pouco significativos face à contínua degradação ambiental, em dezembro de 1983, o secretário geral das Nações Unidas apontou Gro Harlem Brundtland, primeira ministra da Noruega, nessa época, para coordenar uma comissão independente com foco nos problemas relacionados à crise ambiental e ao desenvolvimento. Essa iniciativa ficou conhecida por Comissão Mundial sobre Meio Ambiente e Desenvolvimento e teve seus trabalhos encerrados em 1987 com a publicação do relatório "Nosso Futuro Comum", também conhecido como "Relatório Brundtland".

Foi no relatório Brundtland que a expressão "desenvolvimento sustentável" foi pioneiramente definida como "o desenvolvimento que atende às necessidades presentes sem comprometer a habilidade das gerações futuras em atenderem às suas próprias necessidades". O relatório sugeria que o "desenvolvimento sustentável" deveria ser reconhecido como o propósito orientador da ação política e econômica internacional. Como observa Boff (2012), desde então, a ideia de desenvolvimento sustentável ganhou espaço e foi rapidamente incorporada ao discurso governamental, ambientalista e empresarial.

Em meados dos anos 1990, o conceito de desenvolvimento sustentável foi traduzido pelo consultor Britânico John Elkington no modelo que contemporaneamente tem orientado a ação e prática empresarial para a (pretensa) sustentabilidade. Elkington (1997) sugeriu que a atividade corporativa orientada pela lógica do desenvolvimento sustentável é aquela que, ao mesmo tempo, produz lucros, é socialmente justa e ambientalmente correta. Esse modelo ficou conhecido como o tripé do desenvolvimento sustentável ou Triple Bottom Line (3BL): Profits, People, Planet, amarrando num único conceito os ideais da prosperidade econômica, qualidade ambiental e justiça social. Mais precisamente, presume que o sucesso de uma organização empresarial deve ser mensurado não apenas em face de variáveis financeiras, mas também pelo 
seu desempenho social e ambiental. Notavelmente, organizações como a Global Reporting Initiative e a AccountAbility estão entre os principais promotores desse conceito, cujos relatórios de desempenho, considerando as três dimensões do desenvolvimento sustentável, atualmente, é adotado pelas principais corporações mundiais (NORMAN e MACDONALD, 2004).

\section{Princípios Ideológicos do Desenvolvimento Sustentável no Contexto do Capitalismo}

Para Marx (1946), o sistema de produção capitalista é resultado do desenvolvimento anterior das áreas econômicas, políticas e ideológicas. Nesse foco, a história apresenta-se como resultado das contradições, cujas forças produtivas de uma época são superadas por outras e responsáveis por estruturar uma nova forma de organização produtiva. $\mathrm{O}$ sistema de produção capitalista está baseado na exploração do capital sobre o trabalho, forma de exploração que difere do sistema escravo porque, no capitalismo, as pessoas precisam ser "livres" para vender sua força de trabalho. O capitalista, no entanto, pagará em forma de salário pelo trabalho em função da demanda de forças de trabalho disponíveis para serem exploradas. No desenvolver da história do atual sistema econômico, várias são as racionalidades que mascaram ou simplesmente negam que essa realidade ainda seja a dominante. Tais racionalidades fazem parte de uma ideologia que se institui como forma de promover a reprodução histórica do sistema de produção de capital.

O que caracteriza o sistema de produção capitalista hoje é sua incontrolabilidade (MÉSZÁROS, 2002), ou seja, a forma como o capital se reproduz como sistema organizador total da vida em sociedade sem que se possa, de forma consciente e autônoma por parte dos indivíduos ou de coletivos organizados, frear o processo de acumulação infinita do capital. Somente uma totalidade social poderia modificar essa realidade, mas isso parece pouco provável, dado que a consciência dos coletivos pouco questiona sobre as contradições do sistema econômico capitalista. Por esse motivo, Horkheimer (2000) afirma que o capitalismo é um sistema totalitário, por estruturar as dimensões pragmáticas da vida dos indivíduos (sobretudo a produção da própria existência) e por criar racionalidades baseadas na lógica instrumental.

Hoje se tem uma ordem de reprodução sociometabólica do capital (MÉSZÁROS, 2002). Além de toda uma estruturação de exploração do capital sobre o trabalho, como ocorre nos sistemas produtivos em geral (nas indústrias, no comércio, nas grandes e pequenas empresas em geral), a atual fase de desenvolvimento das forças produtivas está amparada por um sistema financeiro responsável por intensificar o que se tornou a principal mercadoria hoje, o próprio capital na forma de dinheiro, recursos financeiros, ativos, e demais.

Atrelada às condições concretas de reprodução do sistema capitalista como desenvolvimento histórico, instituiu-se a ideologia que se torna cada vez mais importante para a reprodução sociometabólica do capital. O poder da ideologia (MÉSZÁROS, 2004) consiste em criar sistemas culturais, políticos e imaginários que legitimam a exploração, fomentam as ilusões e alienam os indivíduos em relação às formas destrutivas, assim como o sistema de produção capitalista se reproduz explorando os indivíduos, destruindo as condições naturais e eliminando as possibilidades de que as relações humanas sejam de fato a centralidade do processo civilizatório. Nesse caso, sobressai que uma das mais importantes formas ideológicas do capitalismo tardio é o desenvolvimento sustentável.

\section{Promessa capitalista e a centralidade do mercado}

O projeto histórico das sociedades capitalistas se estabelece com base na promessa burguesa de prosperidade social a partir do desenvolvimento capitalista, especialmente, no século XIX, quando essa visão utópica se articula com os discursos proferidos pela ciência, pela filosofia e pela religião, elegendo como questão 
central a expansão da economia de mercado como única saída para as sociedades civilizadas (POLANYI, 2000). Como sugere o historiador Eric Hobsbawm:

\begin{abstract}
O triunfo global do capitalismo é o tema mais importante da história nas décadas que se sucederam a 1848. Foi o triunfo de uma sociedade que acreditou que o crescimento econômico repousava na competição da livre iniciativa privada, no sucesso de comprar tudo no mercado mais barato (inclusive trabalho) e vender no mais caro. Uma economia assim baseada e, portanto, repousando naturalmente nas sólidas fundações de uma burguesia composta daqueles cuja energia, mérito e inteligência os elevou a tal posição, deveria assim se acreditava - não somente criar um mundo de plena distribuição material mas também de crescente esclarecimento, razão e oportunidade humana, de avanço das ciências e das artes, em suma, um mundo de contínuo progresso material e moral. (HOBSBAWM, 2000, p. 19).
\end{abstract}

Todavia, a promessa burguesa da prosperidade do mundo pelo desenvolvimentismo capitalista não foi cumprida, por causa dos problemas que a manutenção desse sistema engendrava para a sociedade. Mesmo assim, ao longo de toda sua trajetória de autoafirmação, o capitalismo em suas várias facetas - mercantil, industrial, monopolista e de Estado - sustentou-se pelo discurso ideológico, proferido sob a chancela do academicismo cientificista e das estruturas de poder do Estado moderno (ALTHUSSER, 1999). Como principal ideologia de sustentação, a teoria econômica clássica se constitui como um dos principais pilares do capitalismo, dando-lhe os argumentos necessários para justificar sua expansão e critérios de articulação social e política. Por sua vez, a legitimação do projeto capitalista pela teoria econômica se deu com universalização das relações de mercado como único critério de articulação da vida social (POLANYI, 2000; DOBB, 1977). Realmente, a partir do século XIX, o mercado de livre comércio e o ganho capitalista constituem critérios de prosperidade, não só econômica, mas também social e religiosa (WEBER, 2004). Assim, gradualmente, a política dos governos dos Estados capitalistas - sejam aqueles do capitalismo privado ou do capitalismo de Estado (DOBB, 1977) - passa a ter por única premissa a manutenção de uma economia de mercado, em que todos os enclaves da sociedade se subverteriam e naturalmente se organizariam em um pretenso equilíbrio (expresso na teoria econômica pelo ótimo de Pareto). No âmbito das organizações econômicas ou mesmo das organizações formais de interesse público, a centralidade do mercado se manifesta pelo imperativo de uma racionalidade econômica, de natureza instrumental e isenta de valores éticos, e sem qualquer orientação para o bem comum (RAMOS, 1989).

De acordo com os historiadores e críticos do capitalismo, duas importantes consequências perniciosas da hegemonia da orientação para o mercado, como critério de organização social e política, marcam o fim da autonomia do trabalhador, decorrente da perda do controle do processo de trabalho, e pelo fim da economia de subsistência. Ou seja, antes do advento das sociedades capitalistas, mesmo com a vigência de outras formas de dominação (a escravidão na antiguidade e a servidão na idade média), o trabalhador detinha o controle do seu processo de subsistência. Isso porque ele controlava o tempo e a realização do processo de trabalho dos bens que produzia, bem como lhe era permitida a produção de subsistência (mesmo que precária). Com a racionalização da produção para o mercado, o trabalho torna-se mercadoria e se subverte à lógica de maximização do ganho capitalista, deixando de ser ofício para se fragmentar com a divisão interna do processo produtivo (GORZ, 1980). Condicionada pela remuneração assalariada, a dedicação exclusiva à tarefa fragmentada e especializada imposta pela organização fabril e o modo de produção capitalista, além de sujeitar a produção de bens ao critério do valor de troca, arremataram de vez a economia de subsistência, uma vez que o trabalhador ficou impedido de produzir os próprios bens de uso, que passaram a ser adquiridos exclusivamente pela renda advinda da venda de sua força de trabalho. Um bom exemplo dessa mudança é o caso do desenvolvimento da economia industrial no Brasil, ocorrida sob os auspícios da produção agroexportadora do café, tendo em conta a substituição da mão de obra escrava pela mão de obra assalariada na lavoura (DEAN, 2001). 


\section{Capitalismo, desigualdade social e hegemonia do sistema financeiro}

A despeito dos esforços da ideologia progressista que suporta o sistema capitalista, a lógica de mercado carrega consigo a contradição do desequilíbrio social. Na verdade, considerando que o desenvolvimento do capitalismo no século XX se deu pela concentração monopolista - mais evidente após a segunda guerra mundial (DOBB, 1987) - a desigualdade social se torna uma baliza nas sociedades capitalistas, por representar um mecanismo de reprodução desse sistema. Como assevera Hobsbawm (2000), a era de afirmação do capitalismo é marcada pela desigualdade, na medida em que o capitalismo industrial vai tomando corpo em escala global, ocultando sua face perversa pela máxima do progresso tecnológico e econômico, grande meta a ser perseguida pelos países e pelos indivíduos isolados. Assim, se havia pobreza em uma nação, é porque esta era subdesenvolvida, sendo papel do governo adotar políticas macroeconômicas que privilegiassem a economia de acumulação capitalista, a despeito de essas políticas comprometerem as condições mínimas de segurança social (DOBB, 1977). Sob o ponto de vista individual, se alguém não era miserável ou excluído, isso se devia a sua incapacidade empreendedora, pois, em uma democracia capitalista, todos têm (supostamente) direitos iguais, mas nem todos são considerados capazes. Como bem assegura Hobsbawm sobre a condição social do progresso capitalista, este se apresenta de forma dramática para a maioria esmagadora da população mundial:

O 'drama do progresso' é uma metáfora. Mas para duas espécies de pessoas era uma realidade literal. Para milhões de pobres, transportados para um novo mundo frequentemente transpondo fronteiras e oceanos, ele significou uma mudança de vida cataclísmica. Para os povos do mundo fora do capitalismo, que eram agora atingidos e sacudidos por ele, significou a escolha entre uma resistência passiva em nome de suas antigas tradições e modos de ser e um traumático processo de tomada das armas do Ocidente para voltá-las contra os conquistadores: de compreensão e manipulação do progresso por eles mesmos (HOBSBAWM, 2000, p. 23).

Dentro do sistema capitalista, a exploração histórica revelada pelo trecho acima ocorre no sentido microssocial com a exploração do trabalhador, que, como já sinalizado, perde sua autonomia de subsistência no momento em que ele se torna refém da fragmentação interna do ofício e da remuneração assalariada (GORZ, 1980). Sob o ponto de vista macro, a exploração ocorre pela ação imperialista das nações industrializadas mais avançadas sobre os países economicamente atrasados, sustentada pela ideologia do desenvolvimento e pelo neocolonialismo que tem início no século XIX. Quanto ao desenvolvimentismo, a crença de que as nações de capitalismo mais avançado são exemplos de prosperidade a serem seguidos impetraram a noção de subdesenvolvimento para as nações exploradas pela lógica do capitalismo corporativo, uma ideologia que, ao mesmo tempo, condiciona o explorado a perseguir os valores do capitalismo como seus, mas também o aprisiona na espécie de submissão, baseada na falsa noção de que sua incapacidade advém de princípios estruturais que impedem o verdadeiro desenvolvimento capitalista (LIPIETZ, 1987).

A crise social de exploração do trabalhador e dos excluídos nas sociedades capitalistas também se revela pelo fato de o fim último do capitalismo ser o dinheiro. Nesse sentido, não se considera o dinheiro um meio de equivalência - algo presente na história das civilizações antes mesmo da emergência do capitalismo (DOBB, 1987) - mas o dinheiro em estado puro, expresso pela constituição das finanças como finalidade última das políticas públicas e do interesse privado (SANTOS, 2005). Historicamente, o sistema financeiro se articula com o advento do capitalismo monopolista e com o fim do padrão-ouro de legitimação do livre mercado em dimensões globais (POLANYI, 2000). Mesmo assim, sua lógica já foi identificada pela fórmula apontada por Marx em sua crítica ao capital: a fórmula "dinheiro - mercadoria - dinheiro", que subverte o valor de uso pelo valor de troca e se sustenta na exploração do trabalho alheio no processo de acumulação do capital (MARX, 2002). 


\section{Capitalismo como sistema de consumo ilimitado}

A lógica da acumulação monopolista e de reprodução infinita do capital, além de trazer os ciclos de crise interna no sistema (BRAGA, 1996; KATZ e COGGIOLA, 1996; MÉSZÁROS, 2007), como crises conjunturais de acumulação do capital, revela uma crise quanto ao limite material dos recursos da natureza disponíveis para a produção de mercadorias. O princípio da acumulação capitalista, por estar centrado no desenvolvimento do mercado e na crescente acumulação de capital, fez com que a eficiência da produção industrial em escala rapidamente se tornasse insuficiente como único critério de construção de valor de mercado; bastou replicar as modernas técnicas de produção industrial - sejam as tecnologias de produção em escala (LANDES, 2005) ou as tecnologias de controle administrativo (TRAGTENBERG, 1989) - para que a vantagem pela produção eficiente deixasse de ser o único critério de diferenciação. Nesse momento, constitui-se um novo modelo econômico, mais refinado e que não abandona o grande potencial de exploração da força de trabalho pela produção industrial, modelo este centrado duplamente na sofisticação tecnológica e no desejo de consumo. Tendo sido conhecido como modelo fordista de produção, esse sistema condiciona a economia capitalista mundial ao monopólio da sociedade de consumo de massas (HARVEY, 2007) e subverte a lógica finita dos recursos naturais ao uso ilimitado dos recursos na produção do consumo e acumulação do capital.

Assim, na produção capitalista que se renova com o fordismo, a lógica do consumo desenfreado emerge como critério de prosperidade. Produzir indefinidamente mais e mais bens de consumo, produzir novos desejos para aumentar o consumo, manter empregada a força de trabalho para garantir a renda e o consumo, essa era a máxima que ficou conhecida como o pacto fordista (LIPIETZ, 1987). A esse respeito, Illich (2000) chama a atenção para a questão da necessidade socialmente constituída dentro do projeto desenvolvimentista, um importante recurso ideológico que serve ao capitalismo de consumo e que é instituído como planificação de Estado. Segundo o autor, as necessidades artificiais são importantes sustentáculos do programa de desenvolvimento do pós-guerra, liderado pela maior potência capitalista do mundo, e representava a idealização que justificava a produção desenfreada que o capitalismo exigia para se manter vigoroso. Como sugere o autor:

A busca de desenvolvimento por meios políticos introduziu as necessidades no discurso político ocidental. Em seu discurso inaugural de 1949, o Presidente dos Estados Unidos, Harry Truman, pareceu bastante convincente quando defendeu a posição de que os Estados Unidos deveriam intervir em outros países para criar 'o progresso industrial' a fim de 'melhorar o padrão de vida' nas 'áreas subdesenvolvidas' do mundo. Truman não falou de revolução. Seu objetivo era 'diminuir o fardo que os pobres carregam' e, segundo ele, essa façanha poderia ser realizada com a produção de 'mais alimentos, mais roupas, mais materiais para a construção de casas e mais energia mecânica'. Para Truman e seus consultores, 'a expansão da produção era a chave para a prosperidade e para a paz (ILLICH, 2000, p. 159-160).

A reflexão de Illich sobre o discurso de Truman, acerca da política desenvolvimentista norte-americana durante o período da Guerra Fria, aponta que esse esforço reflete, antes, a preocupação de que a lógica social e política centrada de produção de mercadorias e acumulação de capital precisa dispor para a autorreprodução. Observado com base no conceito de sustentabilidade, o desenvolvimentismo se apresenta como um projeto irreconciliável com as condições de sobrevivência de uma sociedade humana marcada por limites do espaço natural que lhe condiciona a vida (SACHS, 2000a).

\section{Sustentabilidade Impossível: uma Crítica}

Sustentabilidade refere-se à qualidade de sustentável, isto é, de manter algo "mais ou menos constante, ou estável, por longo período" (FERREIRA, 2012). Em sua versão sustentável, o ideal desenvolvimentista do 
modo de produção capitalista pressupõe a possibilidade do aumento da riqueza e prosperidade social sem que isto necessariamente implique aumento da degradação ambiental e das injustiças sociais. Entretanto, essa pretensão do sistema capitalista é essencialmente utópica, tendo em vista que, considerando seus fundamentos históricos, os princípios de sustentação social e política do capitalismo tardio são irreconciliáveis com a apropriada atenção aos problemas ecológicos e sociais contemporâneos, sobretudo, ao se notar que os elementos constituintes do capitalismo não se desvinculam de uma concepção política liberal, centrada da hegemonia de uma ideologia burguesa que apregoa o sucesso econômico como o único caminho possível para a sociedade.

Dessa forma, é preciso escrutinar a ideia de sustentabilidade da mesma forma que vêm sendo postos ao crivo crítico, outros conceitos liberais centrados no projeto capitalista - como, por exemplo, ocorre com a crítica ao conceito de desenvolvimento (SACHS, 2000b) e ao conceito de globalização (SANTOS, 2005). Essa reflexão crítica somente se torna possível ao se observar a contradição interna do capitalismo, vislumbrando a impossibilidade de realização do equilíbrio de Pareto entre as questões sociais, econômicas e ecológicas dentro de um projeto social e político articulado exclusivamente no interesse da acumulação monopolista das grandes corporações capitalistas (SANTOS, 2005). Nesse intuito, apresentam-se alguns aspectos que sugerem as contradições não resolvidas no conceito dominante de desenvolvimento sustentável tal qual manifesta no suposto equilíbrio do modelo Triple Bottom Line.

Notadamente, a despeito da retórica conservacionista, os pressupostos do desenvolvimento sustentável não rompem com a ideologia do crescimento organizacional, pelo contrário, em seu reconhecido pilar econômico-financeiro da lucratividade, presume a possibilidade da contínua e indefinida acumulação dos lucros. Ao contrário dos processos de desenvolvimento biológico que, por estarem inseridos no ciclo da vida, iniciam sua degeneração ao atingirem a maturidade, os pressupostos do desenvolvimento sustentável não preveem limites para o crescimento econômico. Da mesma forma, não indica qual o estágio de maturidade no processo de desenvolvimento. Desde que o relatório pioneiro do Clube de Roma lançou a tese sobre os limites do crescimento, diversos estudos e autores têm apontado a insustentabilidade de sistemas orientados pelo crescimento ilimitado (SCHUMACHER, 1973; GEORGESCU-ROEGEN, 1975; SIMMS, JOHNSON e CHOWLA, 2010) e defendido a lógica de se imporem limites ao crescimento (LATOUCHE, 2009; JACKSON, 2009). Nesses termos, na medida em que procura preservar a natureza sem reconhecer a prerrogativa de limitar o consumo e a expansão econômica das organizações (SHRIVASTAVA, 1995), a lógica dominante do desenvolvimento sustentável torna-se uma impossibilidade.

Não obstante seu compromisso com a justiça social, os pressupostos dominantes do desenvolvimento sustentável ignoram o fato de a organização capitalista ser inerentemente estabelecida em princípios de desigualdade tipicamente expressos na apropriação dos meios de produção, divisão do trabalho, especialização e hierarquização. Desta forma, ignora que em sua estrutura, as organizações capitalistas carecem de solidariedade interna uma vez que legitima a distribuição dos resultados da atividade empresarial de forma desproporcional em favor dos níveis superiores de direção. De acordo com o Economic Policy Institute (EPI, 2011), enquanto em 1965 a média salarial de um Chief Executive Officer nos Estados Unidos era de aproximadamente 24 vezes maior que a do trabalhador médio em 2009, essa razão foi de 185 vezes, tendo atingido 300 vezes em 2000. Outra contundente evidência da injustiça social inerente aos modelos organizacionais dominantes é apontada pelo relatório do New Economics Foundation (SIMMS, JOHNSON e CHOWLA, 2010, p. 18). De acordo com o relatório "Between 1990 and 2001, for every $\$ 100$ worth of growth in the world's income per person, just \$0.60, down from $\$ 2.20$ the previous decade, found its target and contributed to reducing poverty below the \$1-a-day line". Além disso, o relatório indica que nos moldes atuais de produção e redistribuição da riqueza para garantir cada dólar utilizado na redução da pobreza seria necessário o aumento do consumo e produção global em 166 dólares. Uma equação de difícil conciliação em face das atuais contingências ambientais.

Observa-se ainda que o modelo dominante do desenvolvimento sustentável tanto não questiona a hegemonia do mercado como orientador da atividade produtiva, como pouco discute até que ponto a lógica de produção 
para o mercado é coerente com o propósito de manutenção da vida no planeta e da redução das injustiças sociais. Há sérias evidências de que o atual modelo de produção para o mercado, em contraponto à produção para subsistência (SAHLINS, 1978) tem papel central na degradação ambiental. Exemplo contundente de que lógica de produção para o mercado contradiz o pressuposto de preservação dos recursos ambientais e da justiça social pode ser verificado em recente estudo produzido pela Organização das Nações Unidas para a Alimentação e Agricultura (FAO, 2011). O relatório indica que, no âmbito global, aproximadamente um terço dos alimentos produzidos para consumo humano são desperdiçados. Em última análise, isso significa que uma quantidade imensa de recursos utilizados na produção de alimentos é empregada em vão, e que boa parte dos gases responsáveis pelo efeito estufa emitida na produção de alimentos poderia ser evitada, e que, a despeito disso, milhares de pessoas ainda passam fome no planeta.

Finalmente, nota-se que o conceito de desenvolvimento sustentável, tal como proposto no Relatório Brundtland, fundamenta-se no mito das necessidades (ILLICH, 2000). Nesses termos, apesar da retórica conservacionista, esse relatório corrobora a perspectiva desenvolvimentista do capital que entende o ambiente como "meio" ou repositório de recursos a serem utilizados para satisfação das necessidades humanas. Segundo, entende necessidades baseadas de uma perspectiva ocidental globalizante que ignora as inúmeras diferenças culturais entre as nações. Terceiro, tanto não distingue a diferença entre desejos e necessidades, como não reconhece que necessidades são socialmente construídas. Daí, pergunta-se, quais serão as necessidades das gerações futuras? (Novos modelos de telefones celulares? Carros maiores e mais sofisticados?). Sobretudo, verifica-se que o conceito é essencialmente antropocêntrico, uma vez que ignora as "necessidades" dos demais participantes da comunidade da vida.

\section{Considerações finais}

Sob os pressupostos da Teoria Crítica, o discurso do desenvolvimento sustentável apresenta-se como contraditório em si mesmo. O conceito surge em razão do processo de degradação econômica, fragilidade política e destruição da natureza como tentativa de amenizar o gérmen do sistema de produção capitalista: exploração, destruição e alienação.

Os estudos sobre desenvolvimento sustentável estão baseados na ciência tradicional, ou seja, caracterizam-se por aquilo que Horkheimer chamou de teoria tradicional. Desse modo, o conceito apresenta-se de forma dissociada da sua construção histórica, das contradições inerentes ao próprio processo histórico que o originou, tornando-se uma ideia automática, instrumentalizada, uma coisa a ser disseminada sem questionamentos ou reflexões profundas. Baseada na teoria tradicional, a proposta de desenvolvimento sustentável apresenta-se também como concepção aparente, que mascara as contradições da relação dialética destruição/sustentabilidade: a sustentabilidade torna-se cada vez mais importante na medida em que a destruição econômica e da natureza se intensificam. É por esse movimento dialético que não teve sentido a concepção de sustentabilidade em contextos históricos em que a destruição econômica e da natureza não se faziam presentes.

Em virtude dessa lógica, a racionalidade predominante sobre o desenvolvimento sustentável ampara-se em uma epistemologia baseada em um pragmatismo de foco utilitarista, ou seja, a sustentabilidade apresenta-se como um discurso necessário e útil na medida em que legitima as práticas das empresas e dos "intelectuais" que servem aos interesses das elites econômicas vinculadas ao sistema de capital.

Como conceito, a ideia de desenvolvimento sustentável é apresentada de forma dissociada da sua concepção social-histórica, ou seja, a sua concepção é apresentada sem levar em consideração seus limites, a sua relação com o real. É apresentada como racionalidade absoluta, mas na realidade tem pouca sustentação por servir a qualquer momento, em qualquer situação dentro da lógica espacial e temporal estática e imutável. Para as organizações ou intelectuais que se apropriam das concepções de sustentabilidade, o que importa é encaixálas dentro dos contextos e dos discursos que atendam aos seus interesses pragmáticos. 
Desenvolvimento sustentável é também ideologia, pois mascara e distorce o real ao fazer das suas ideias a versão dominante, mas não verdadeira de algo, e seu compartilhamento como necessidade central nos discursos empresariais demonstra como a ideologia se impôs ante a reflexão permanente e contínua da realidade, motivando justamente o aparecimento da sustentabilidade. O termo surgiu e ganhou força como forma de promover uma ideologia materializada em ações modestas para dissuadir a opinião pública, evitando que a realidade se apresente como ela realmente é. A sustentabilidade é um termo contraditório por se apresentar como uma verdade salvadora, como um mito salvador ante o apocalipse eminente.

A sustentabilidade apresenta-se como termo esclarecido, ou seja, como algo instrumental que afeta a sociedade tal como qualquer outro conhecimento científico das ciências tradicionais. Para que ela se torne conhecimento emancipado para o indivíduo e para a coletividade, precisa fazer parte de uma práxis transformadora, em que a condição humana seja o fim em si mesma e não os interesses econômicos concentrados nas mãos de poucos.

De forma prática, trata-se simplesmente de prevenir as situações contraditórias facilmente encontradas nas organizações, a exemplo das ocorrentes em uma fábrica de produtos altamente poluentes, mas que tem programas de reciclagem somente para assegurar a seus funcionários a sensação de estarem fazendo a coisa certa, ou de amenizarem seu sentimento de culpa.

\section{Referências}

ADORNO, T. W. O ensaio como forma. In: Adorno, T.W. Sociologia. São Paulo: Editora Ática, 1986. p. 15-45. .; HORKHEIMER, M. Dialética do Esclarecimento. Rio de Janeiro: Jorge Zahar, 1985.

ALCADIPANI, R.; TURETA, C. Teoria ator-rede e estudos críticos em administração: possibilidades de um diálogo. Cad. EBAPE.BR, v. 7, n. 3, p. 405-418, 2009.

ALTHUSSER, L. Sobre a Reprodução. Petrópolis, RJ: Editora Vozes, 1999.

ANDERY, M. A. et al. Para compreender a ciência. Rio de Janeiro: Garamond, 2007.

BOFF, L. Sustentabilidade: O que é - o que não é. Petrópolis: Vozes, 2012.

BOTTOMORE, T. B. The Frankfurt School. London: Routledge, 1984.

Dicionário do Pensamento Marxista. Rio de Janeiro: Jorge Zahar, 1998.

BRAGA, R. A Reestruturação do Capital: Um Estudo sobre a Crise Contemporânea. São Paulo: Xamã, 1996.

CARSON, R. Silent spring. Boston, MA: Houghton Mifflin; Riverside Press, 1962.

DEAN, W. A industrialização de São Paulo: 1880-1945. 4. ${ }^{a}$ ed. São Paulo: Bertrand Brasil, 2001.

DOBB, M. Teorias do valor e distribuição desde Adam Smith. Lisboa: Editora Presença, 1977.

. A evolução do capitalismo. 9. ${ }^{a}$ ed. Rio de Janeiro: LTC, 1987.

ELKINGTON, J. Cannibals with Forks: the Triple Bottom Line of 21st Century Business. Oxford: Capstone, 1997.

EPI. The State of Working America: Inequality. Economic Policy Institute, 2011. Disponível em: $<$ http://stateofworkingamerica.org/charts/ratio-of-average-ceo-total-direct-compensation-to-a $>$. Acesso em fevereiro de 2012. 
FAO. Global Food Losses and Food Waste. Rome: Food and Agriculture Organization of the United Nations, 2011.

FARIA, J. H. Consciência crítica com ciência idealista: paradoxos da redução sociológica na fenomenologia de Guerreiro Ramos. Cad. EBAPE.BR, v. 7, n. 3, p. 420-446, 2009.

FERREIRA, A. B. H. Sustentável. Dicionário Eletrônico Aurélio. Curitiba: Editora Positivo, 2012.

GEORGESCU-ROEGEN, N. Energy and economic myths. Southern Economic Journal, v. 41, n. 3, p. 347-381, 1975.

GORZ, A. (Org.). Crítica da divisão do trabalho. São Paulo: Martins Fontes, 1980.

HARVEY, D. Condição pós-moderna: uma pesquisa sobre as origens da mudança cultural. 16. a ed. São Paulo: Loyola, 2007.

HOBSBAWM, E. A era do Capital: 1848-1875. 5. a ed. Rio de Janeiro: Paz e Terra, 2000.

HORKHEIMER, M. Ocaso. España, Editorial Anthropos, 1986.

. Teoría Crítica I - Max Horkheimer. São Paulo: Perspectiva: Editora da USP, 1990.

. Teoria Tradicional e Teoria Crítica. In: Horkheimer, M.; Adorno, T. W. Textos Escolhidos. Coleção Os Pensadores. São Paulo: Nova Cultural, 1991a.

. Filosofia e Teoria Crítica. In: Horkheimer, M.; Adorno, T. W. Textos Escolhidos. Coleção Os Pensadores. São Paulo: Nova Cultural, 1991b.

Eclipse da Razão. São Paulo: Centauro Editora, 2000.

ILLICH, I. Necessidades. In: Sachs, W. (Ed.) Dicionário do desenvolvimento: guia para o conhecimento como poder. Petrópolis: Vozes, 2000. p. 155-172.

JACKSON, T. Prosperity withouth growth? The transition to a sustainable economy. London: Sustainable Development Commission, 2009.

KATZ, C; COGGIOLA, O. Neoliberalismo ou Crise. São Paulo: Xamã. 1996.

KOSELLECK, R. Passado Futuro: contribuição à semântica dos tempos históricos. Rio de Janeiro: Contraponto e Ed PUC-Rio, 2006.

LANDES, D. Prometeu desacorrentado: transformação tecnológica e desenvolvimento industrial na Europa ocidental de 1750 até os dias de hoje. Rio de Janeiro: Campus/Elsevier, 2005.

LATOUCHE, S. Farewell to growth. Cambridge: Polity, 2009.

LIPIETZ, A. Miragens e milagres: problemas da industrialização no Terceiro Mundo. São Paulo: Nobel, 1987.

MARX, K. Contribuição da economia política. São Paulo: Editora Flama, 1946.

O capital. 20. ed. Rio de Janeiro: Civilização Brasileira, v. 1, 2002.

MEADOWS, D. The limits to growth: a report for the Club of Rome's project on the predicament of mankind. New York: University Books, 1972.

MÉSZÁROS, I. Para além do capital. São Paulo: Boitempo Editorial; Campinas: Editora da Unicamp, 2002. O poder da ideologia. São Paulo: Boitempo Editorial, 2004.

O desafio e o fardo do tempo histórico. São Paulo: Boitempo, 2007. 
MISOCZKY, M. C. et al. Bloch, Gramsci e Paulo Freire: referências fundamentais para os atos da denúncia e do anúncio. Cad. EBAPE.BR, v. 7, n. 3, p. 448-471, 2009.

NORMAN, W.; MACDONALD, C. Getting to the Bottom of “Triple Bottom Line”. Business Ethics Quarterly, v. 14, n. 2, p. 243-262, 2004.

PAUlA, A. P. P.; MARANHÃO, C. M. S. A.; BARROS, A. N. Pluralismo, pós-estruturalismo e "gerencialismo engajado": os limites do movimento critical management studies. Cad. EBAPE.BR, v. 7, n. 3, p. 393-404, 2009.

POLANYI, K. A grande transformação: as origens de nossa época. 2. ed. Rio de Janeiro: Campus, 2000.

RAMOS, A. G. A nova ciência das organizações: uma reconceituação da riqueza das nações. 2. ed. Rio de Janeiro: FGV, 1989.

SACHS, W. Meio Ambiente. In: Sachs, W. (Ed.). Dicionário do desenvolvimento: guia para o conhecimento como poder. Petrópolis: Vozes, 2000a, p. 117-131.

(Ed.) Dicionário do desenvolvimento: guia para o conhecimento como poder. Petrópolis: Vozes, $2000 \mathrm{~b}$.

SAHLINS, M. Stone Age Economics. London: Tavistock Publications, 1978.

SANTOS, M. Por uma outra globalização: do pensamento único à consciência universal. 12. ed. Rio de Janeiro: Record, 2005

SCHUMACHER, E. F. Small is beautiful: economics as if people mattered. New York: Harper \& Row, 1973.

SHRIVASTAVA, P. The role of corporations in achieving ecological sustainability. Academy of Management Review, v. 20, n. 4, p. 936-960, 1995.

SIMMS, A.; JOHNSON, V.; CHOULA, P. Growth isn't possible: why we need a new economic direction. London: New Economics Foundation, 2010.

TENÓRIO, F. G. A modernidade e a pós-modernidade servidas em dois jantares. Cad. EBAPE.BR, v. 7, n. 3, p. $472-$ 491, 2009.

TRAGTENBERG, M. Administração, poder e ideologia. São Paulo: Cortez, 1989.

WEBER, M. A ética protestante e o "espírito" do capitalismo. São Paulo: Companhia das Letras, 2004. 